Disponível em

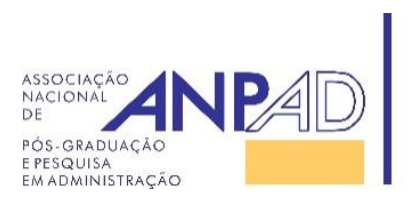

http://www.anpad.org.br/rac

RAC, Rio de Janeiro, v. 21, n. 2, art. 5,

pp. 227-248, Mar./Abr. 2017

http://dx.doi.org/10.1590/1982-7849rac2017150300

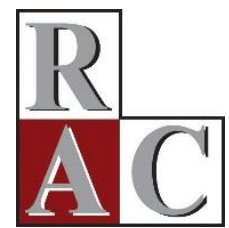

(c) EY

\title{
O Vir a Ser da Estratégia como uma Prática Social
}

\author{
How Strategy Becomes a Social Practice
}

Natália Rese ${ }^{1}$

Flávia Harumi Souza Kuabara ${ }^{1}$

Eduardo Guedes Villar ${ }^{1}$

Jane Mendes Ferreira ${ }^{1}$

Universidade Federal do Paraná ${ }^{1}$

Artigo recebido em 28.10.2015. Última versão recebida em 19.07.2016. Aprovado em 21.07.2016. Publicado online em 28.10.2016. 


\title{
Resumo
}

Esta pesquisa tem por objetivo compreender como a estratégia torna-se uma prática social em contextos submetidos a lógicas diversas da lógica capitalista. O estudo foi desenvolvido a partir de uma pesquisa narrativa em um empreendimento social, tendo esta organização o objetivo de potencializar os resultados de Escolas de Educação Especial por meio da gestão. A análise dos dados deu-se a partir da Tipologia proposta por O'Connor (2002) e das características da narrativa apresentadas por Pentland (1999). Para se tornar uma prática social em um contexto onde não o é, dá-se um exercício qualificado de sensegiving e sensemaking. Como resultados, observam-se: (a) a narrativa desenvolvida na conversação com os investidores é carregada de histórias situacionais; (b) a narrativa desenvolvida na conversação com o público atendido é carregada de histórias genéricas; e (c) o sentido dado pelos estrategistas e construído pelos diferentes praticantes dá-se em um processo narrativo de negociação de significado, cuja legitimidade está assentada nas histórias pessoais, e cuja plausibilidade, nas histórias genéricas e situacionais. Em termos de conclusão, entende-se que a estratégia se torna uma prática social na medida em que seus significados passam a ser compartilhados nesse novo espaço e então orientam as atividades (práxis) cotidianas da estratégia.

Palavras-chave: estratégia como prática social; narrativas; textos da estratégia; sensemaking; sensegiving.

\begin{abstract}
This research aims to understand how strategy becomes a social practice when submitted to various capitalistic logics. The study was developed from a narrative perspective in a social enterprise whose goal is to enhance the results of Special Education Schools through management. Data analysis was based upon the typology proposed by O'Connor (2002) and from narrative features discussed by Pentland (1999). For something to become a social practice in a context where it is not, it undergoes an exercise where it is qualified as sensegiving and sensemaking. Observed results show that: (a) the narrative as developed in conversation with investors is loaded with situational histories; (b) the narrative as developed in conversation with the public is loaded with generic histories; (c) the meaning given by the strategists and constructed by the different practitioners is presented as a narrative about the meaning negotiating process, where legitimacy is based on personal histories and plausibility on generic and situational histories. In conclusion, we understand that strategy becomes a social practice in that its meanings come to be shared in this new space and, thus, come to guide the ordinary activities (praxis) of strategy.
\end{abstract}

Key words: strategy as social practice; narratives; strategy texts; sensemaking; sensegiving. 


\section{Introdução - Era uma vez...}

Esta é a história de uma pesquisa narrativa. Tudo começa na década de 1950 quando, em Harvard/EUA, a disciplina de Política de Negócios (Business Policy) começou a ser repensada e, na década de 1960, assumiu o nome de Estratégia de Negócios, trazendo uma nova concepção para a administração, inserindo, assim, uma dimensão prospectiva e uma postura proativa dos gestores das organizações (Bower, 2008; Vizeu \& Gonçalves, 2010).

Desde o surgimento do campo de estudos da estratégia, diversos significados puderam ser atribuídos a ela (Mintzberg, 2006), todos eles de certa forma significativos para orientar a prática organizacional (Mintzberg, Ahlstrand, \& Lampel, 2000). Essa polissemia faz parte do contexto do entendimento da estratégia como uma prática social, uma vez que são esses significados as ferramentas utilizadas nas atividades do fazer estratégia e, principalmente, a ideia de que administrar as organizações exige uma ação deliberada de análise e planejamento que fundamenta a concepção compartilhada do que seja administrar no mundo das organizações de negócios.

Nesse sentido, o objetivo proposto para esse trabalho é compreender como a estratégia torna-se uma prática social em contextos submetidos a lógicas diversas da lógica capitalista, lócus por excelência da estratégia empresarial e onde ela figura como uma prática social. Dessa problemática e com base em um contexto específico de pesquisa que tem por objeto as organizações que trabalham no terceiro setor, em empreendimentos de natureza social, as quais convivem com uma lógica distinta daquela do contexto dos negócios capitalistas, perguntas específicas de pesquisa podem ser delineadas: a estratégia é uma prática social em qualquer contexto organizacional? As práticas a ela vinculadas são dadas em qualquer contexto organizacional? E qual é o processo de construção dessa prática como social? De que vale essa discussão compreensiva? A dimensão teórica da perspectiva da estratégia como prática social parece esclarecedora e frutífera, no entanto, a compreensão dos métodos empregados pelos sujeitos em ação, na construção ativa do cotidiano, ainda merece atenção (A. D. Brown \& Thompson, 2013; Fenton \& Langley, 2011). Dessa forma, essa pesquisa procura avançar desvelando o processo por meio do qual a estratégia se torna uma prática social, a partir da ação empreendida pelos sujeitos. Para endereçar essa discussão, o estudo foi desenvolvido em um empreendimento social, tendo esta organização o objetivo de potencializar os resultados de Escolas de Educação Especial por meio da gestão, contexto que se entende propício para discutir como lidar com lógicas tão diversas, tais quais são a gestão e a causa social.

A perspectiva da estratégia como prática social surge como parte do movimento da virada prática nos estudos organizacionais (Chia \& McKay, 2007; Rasche \& Chia, 2009; Whittington, 2006), em que importa discutir a estratégia como realização de pessoas nas organizações, em detrimento do entendimento da estratégia como um ativo organizacional (Johnson, Langley, Melin \& Whittington, 2007; Whittington, 2002, 2006). O campo de estudos tornou-se frutífero e discussões sobre o tema tornaram-se abundantes (Jarzabkowski \& Spee, 2009; Rasche \& Chia, 2009; Walter \& Augusto, 2011). Desse panorama, dois pontos podem ser destacados: (a) a profusão de entendimentos a respeito do conceito de prática; e (b) as lacunas de pesquisa que motivam e justificam esta pesquisa.

A perspectiva da estratégia como prática, assim como os estudos organizacionais assentados na ideia de prática social, não são uníssonos a respeito do entendimento de prática (Nicolini, 2012). Podese, no entanto, perceber que, dependendo do foco dos estudos - se em práticas, práxis ou praticantes (Whittington, 2006) - há uma tendência de linhas teóricas de análise. Tal constatação pode ser também observada na construção do primeiro volume do Cambridge Handbook of Strategy as Practice (Golsorkhi, Rouleau, Seidl, \& Vaara, 2010), em que se discutem diferentes perspectivas epistemológicas, teóricas e metodológicas (de natureza antipositivista) que são adequadas para o estudo da estratégia sob a perspectiva da prática. O presente trabalho é motivado pelas lacunas de pesquisa relacionadas à ideia de que a comunidade da estratégia como prática tem dado pequena atenção aos estudos baseados em narrativas (A. D. Brown \& Thompson, 2013; Barry \& Elmes, 1997; Fenton \& Langley, 2011). Sob esse enfoque, compartilha-se o entendimento de Fenton e Langley (2011) de que 
as narrativas se constituem em meios relevantes para a compreensão da polifonia que a perspectiva da estratégia como prática social traz para o campo da pesquisa, permitindo que uma prática de pesquisa "mais sofisticadamente reflexiva" (A. D. Brown \& Thompson, 2013, p. 1144, tradução nossa) seja realizada no campo da estratégia como prática social.

Smets, Greenwood e Lounsbury (2015), por sua vez, encorajam ainda pesquisas que lidem com a aproximação entre a abordagem da estratégia como prática e a complexidade característica de organizações híbridas, como são os empreendimentos sociais. Percebe-se, portanto, que existem poucos estudos que endereçam a pesquisa da estratégia como prática a organizações submetidas a lógicas diversas da lógica capitalista. Ainda que o institucionalismo organizacional trabalhe com a problemática da complexidade originada nas tensões causadas por lógicas institucionais dissonantes (Battilana \& Dorado, 2010; Battilana \& Lee, 2014; Battilana, Sengul, Pache, \& Model, 2014; Jongbloed, 2015), existem poucos estudos sobre estratégia como prática nessas organizações e, os que o fazem, não endereçam a problemática ora apresentada (como exemplos de estudos em organizações que desafiam a lógica capitalista sob a perspectiva da estratégia como prática, têm-se: Dobusch \& Kapeller, 2013; Jäger \& Beyes, 2010; Rouleau, 2010).

Posto isso, inicia-se o trabalho apresentando, as vozes que compõem o coro teórico dessa narrativa e que conferem elementos para que a análise aconteça, destacando-se: (a) o recorte da estratégia como prática social que embasa esta pesquisa; (b) as ideias de sensegiving e sensemaking, processos sob os quais é construído o diálogo entre os diferentes praticantes envolvidos no fazer da estratégia e de onde surge a polifonia que chama a narrativa como mediadora do strategizing; (c) o construto que evidencia a relação entre os textos e os elementos constitutivos do strategizing. A partir disso, trabalha-se a narrativa desta pesquisa, que descreve e analisa os dados e permite que entendimentos conclusivos possam ser sugeridos.

\section{Referencial Teórico - As Vozes desta Conversa}

A estratégia, conforme mencionado na introdução, é um conceito fundamental no mundo dos negócios. Tradicionalmente, tem sido tratada sob uma perspectiva econômica (Johnson et al., 2007). No entanto, em consonância com a virada prática nos estudos organizacionais, que trazem à tona a possibilidade de estudar os elementos que representam comportamentos rotinizados e que sustentam as atividades ordinárias cotidianas nas organizações, a estratégia passa a ser compreendida como uma prática social (Jarzabkowski, 2004, 2005; Jarzabkowski, Balogun, \& Seidl, 2007; Whittington, 1996, 2002, 2004, 2006; Wilson \& Jarzabkowski, 2004). Parte-se da ideia de que a realidade é socialmente construída e que os sujeitos subjetivamente incorporam a dimensão objetiva, que é intersubjetivamente compartilhada para dar sentido à vida cotidiana (Berger \& Luckmann, 2010). Dessa forma, as práticas sociais estão relacionadas ao modo compartilhado que orienta esse desempenho cotidiano: "Uma prática é assim o modo rotinizado como os corpos se movem, como os objetos são usados, como os sujeitos são tratados, as coisas são descritas e o mundo é compreendido" (Reckwitz, 2002, p. 250, tradução nossa), e que se revelam nos discursos, nos artefatos, nos comportamentos dos sujeitos e na vida cotidiana da organização (Meyer, Höllerer, Jancsary, \& Leeuwen, 2013). É por essa razão que, ao estudar a estratégia sob a perspectiva da prática, as atividades (práxis), o que os sujeitos produzem, constroem e reconstroem (práticas), o strategizing, aparecem como dimensões importantes para a compreensão do fenômeno (Whittington, 2006). A estratégia como prática social resgata a preocupação ao nível micro de análise, ao atribuir papel relevante aos praticantes, mas também direciona esforços para a compreensão ao nível macro, na medida em que as práticas sociais estão relacionadas a regras e recursos que estruturam a ação social dos sujeitos (Suddaby, Seidl, \& Lê, 2013). Optamos por discutir essas dimensões da estratégia como prática social com base na proposta narrativa de Fenton e Langley (2011). Com base nessa ideia e valorizando o papel da comunicação organizacional nos estudos da estratégia como prática, Fenton e Langley (2011) incorporam a ideia de que o strategizing está alicerçado nos textos produzidos em torno da estratégia e discutem o modelo inicial de Whittington (2006), elaborado por Jarzabkowski, Balogun, Seidl (2007), da forma representada (e adaptada para esta pesquisa) na Figura 1. 


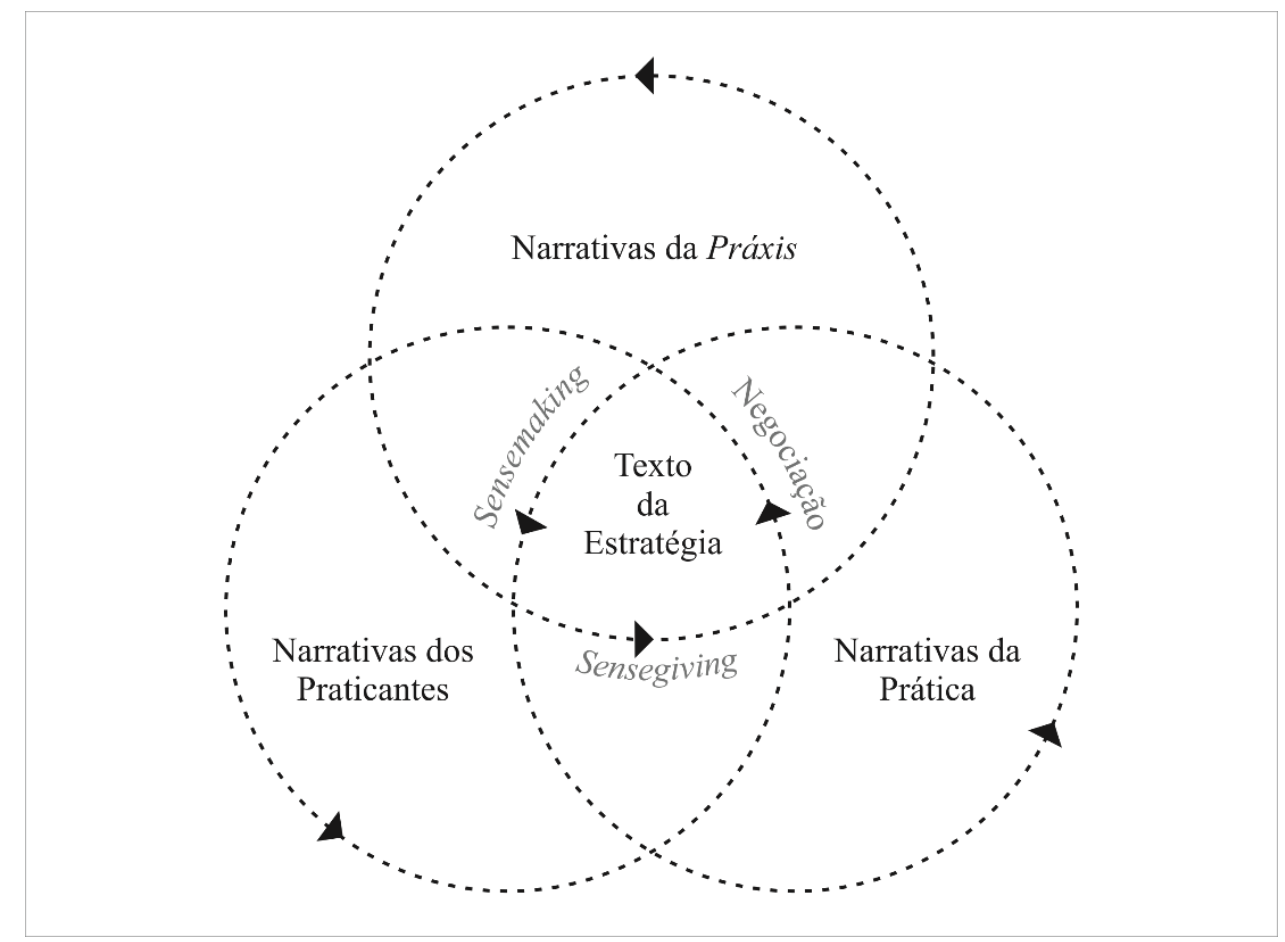

Figura 1. Modelo de Integração das Narrativas à Estratégia como Prática

Fonte: Adaptada de Fenton, C., \& Langley, A. (2011). Strategy as practice and the narrative turn. Organization Studies, 32(9), 1171-1196. http://dx.doi.org/10.1177/0170840611410838

Da Figura 1, entende-se que as três categorias principais da pesquisa da estratégia como prática social podem ser compreendidas a partir da investigação narrativa: à medida que os praticantes - que se constituem como tal a partir do seu envolvimento com a estratégia e, portanto, o entendimento de sua identidade, pode se dar por meio das narrativas construídas em torno desse papel - engajam-se em atividades cotidianas (práxis) relacionadas ao fazer estratégia ou às questões sobre estratégia, eles fazem uso de diferentes histórias que carregam elementos de práticas, com suas regras, recursos, rotinas e aspectos aceitos como dados. Assim, há uma interação entre a construção da identidade dos praticantes, as histórias que os mobilizam cotidianamente no fazer estratégia e os recursos das grandes narrativas que trazem para o fazer cotidiano, de modo a garantir uma construção plausível e coerente em torno da realização cotidiana, o que acaba por construir os textos da estratégia - a partir do que se pode compreender o processo de strategizing como um todo (Fenton \& Langley, 2011; Whittington, 2006).

Partindo dessa perspectiva de Fenton e Langley (2011) e compreendendo ainda as ideias apresentadas por La Ville e Monoud (2003), acrescentou-se ao esquema retratado na Figura 1 que tais textos da estratégia resultam de uma negociação de significados que se dá nos processos de sensegiving e sensemaking, articulados no fazer estratégia. Os estrategistas - praticantes legitimamente reconhecidos - engajam-se em um processo ativo de influenciação de significados a respeito da estratégia, e, por meio do sensegiving, procuram traduzir as grandes narrativas do campo em textos (como os planos de negócios, os planos estratégicos etc.), alicerçando nelas as narrativas locais a respeito da estratégia empresarial. Sobre esses elementos, os demais praticantes da estratégia criam sentido, sensemaking, em busca de orientar o desenvolvimento das atividades cotidianas envolvidas no nível micro da realização da estratégia. Esse processo de negociação - entre sensegiving e sensemaking - é que efetivamente faz surgirem os textos concretos da estratégia que são representativos do processo de strategizing. Em uma perspectiva interacional, La Ville e Mounoud (2006), em consonância com as ideias de Fenton e Langley (2011), propõem que a formação da estratégia consiste em um processo narrativo que organiza a polifonia dentro dos vários elementos que constituem a estratégia vista como uma prática social. Com isso, os autores se referem ao caráter de que o processo de formação da estratégia nunca é controlado por um único ator, ou seja, fazer estratégia é um processo que envolve as vozes de diferentes praticantes. 
Considerando que se objetiva com este estudo compreender como a estratégia pode tornar-se uma prática social em contexto no qual o entendimento da estratégia de negócios não possua um significado compartilhado e orientador da ação, os dois construtos acima citados surgem como fundamentais nesse processo: o de sensemaking e o de sensegiving. O sensemaking corresponde a

um processo, impulsionado pela violação de expectativas, que envolve o tratamento e o agrupamento das lacunas no ambiente, criando significado intersubjetivo por meio de ciclos de interpretação e ação, e assim vivenciando um ambiente mais ordenado a partir do qual outras lacunas possam ser trabalhadas (Maitlis \& Christianson, 2014, p. 67, tradução nossa)

Esse processo, portanto, tem por objetivo a criação de significados de coisas ou eventos novos, ambíguos, confusos e que, portanto, de alguma forma, violam as expectativas dos praticantes (Holt \& Cornelissen, 2014; Maitlis \& Christianson, 2014). Sendo o sensemaking um processo social no qual a identidade é construída intersubjetivamente de forma interacional, pautado em pistas que visam facilitar o processo, é possível introduzir o conceito de sensegiving. O sensegiving, por sua vez, possui um elemento de intencionalidade em que são empreendidos esforços por parte de alguns sujeitos para influenciar a construção de significados dos outros, a partir de uma perspectiva preferencial a respeito da realidade organizacional (Gioia \& Chittipeddi, 1991). Dada a característica da plausibilidade, o sensegiving está relacionado a essa articulação plausível de forma que os sujeitos possam engajar-se na ideia pretendida. Há que se fazer uma ressalva de que esse processo é influenciado, mas dificilmente controlado, uma vez que o processo de construção envolve sempre a negociação de significados.

É nesse sentido, portanto, que surge um argumento importante para este estudo: a condução estruturada do processo de sensegiving, apoiada por artefatos textuais e visuais, pode permitir que pistas plausíveis e estruturadas conduzam o processo de sensemaking de forma a influenciar significativamente na construção do sentido pretendido.

Importante destacar a ideia de que os artefatos visuais e textuais estão amarrados aos contextos culturais em que estão imersos, além do fato de que há uma integração imbricada entre as dimensões verbal e visual, cuja significação não é possível observando-se de forma isolada uma ou outra dimensão. Estar atrelado a um contexto cultural específico significa que os artefatos carregam elementos de práticas sociais representativos de regras e recursos, assim, eles são relevantes quando essas práticas viajam para contextos novos, nos quais elas são passíveis de novos processos de sensemaking e, fundamentalmente, de sensegiving. Não obstante, o imbricamento entre o verbal e o visual dá espaço para o destaque na importância da interação social com base nesses artefatos visuais, dado que a atribuição de significado (sensegiving) e a construção do sentido (sensemaking) são processos necessariamente sociais, interacionais e, portanto, exigem esse momento de articulação verbal, no qual a linguagem adquire papel fundamental.

Diante desses aspectos, o argumento teórico que permeia este estudo é o de que a estratégia é uma prática social no contexto do mundo dos negócios (Nicolini, 2012; Walter, Augusto, \& Fonseca, 2011; Whittington, 1996), no entanto, quando consultores e outros praticantes familiarizados com o campo em questão caminham para outros contextos a fim de trabalhar questões relativas à estratégia, é possível que encontrem dissonância (Jarzabkowski \& Wilson, 2006). Ao encontrar essa dissonância, um processo de sensemaking (Holt \& Cornelissen, 2014) passa a acontecer. Dada a intencionalidade do processo, o sensegiving (Gioia \& Chittipeddi, 1991) a respeito de todos os conceitos, processos e atividades envolvidas no fazer estratégia é empreendido, suportado por artefatos visuais e textos da estratégia (Fenton \& Langley, 2011; Meyer et al., 2013), articulados verbal e discursivamente com o objetivo de atribuição de sentido, evidenciando que as dimensões discursiva e material, conforme discutido anteriormente, são coconstituídas nos textos da estratégia (Fenton \& Langley, 2011). Na interação, o sensemaking (Weick, 1995) ocorre e, à medida que intersubjetivamente se legitimam os significados para esses conceitos, processos e atividades, o sentido de prática social da estratégia é conduzido para um novo campo (La Ville \& Mounoud, 2003). Esse argumento teórico embasa o desenvolvimento de toda a narração e da interpretação dos resultados, que se dá a seguir. 


\section{Procedimentos Metodológicos - Ou sobre o que nos Permite Fazer Ciência}

A pesquisa apresentada é de natureza narrativa. A escolha por uma pesquisa narrativa (Czarniawska, 1998) assenta-se no entendimento de que "nós construímos sentido de nossas vidas criando narrativas que explicam nossas experiências" (Hansen, 2006, p. 1049, tradução nossa), logo, a "análise narrativa é uma busca por significado, não por verdade" (Hansen, 2006, p. 1050, tradução nossa). Justifica-se a opção da pesquisa narrativa por se entender que esse delineamento metodológico permite uma aproximação adequada dos elementos da práxis, das práticas e dos praticantes da estratégia, cuja relação é mediada por narrativas acerca da estratégia (Fenton \& Langley, 2011). Rouleau (2010, p. 258, tradução nossa) afirma ainda que "poucos estudos de uma perspectiva da prática têm utilizado ferramentas metodológicas específicas que são verdadeiramente apropriadas para captar a essência da agência administrativa no processo de strategizing", o que também corrobora com a justificativa para essa abordagem de pesquisa neste estudo. Faz-se, no entanto, necessário esclarecer que sob o título de pesquisas narrativas estão diversas abordagens que vão desde aquelas que trabalham com as análises narrativas sob perspectivas linguísticas (Boje, Haley, \& Saylors, 2016), passando pelos estudos que consideram sob o paradigma narrativo o ser humano como ser narrativo (A. D. Brown \& Thompson, 2013; Cooren, 2001; Fenton \& Langley, 2011; La Ville \& Monoud, 2003, 2010; M. H. Brown, 1990; Samra-Fredericks, 2003), sem esquecer-se daqueles estudos que trabalham com as narrativas a partir dos métodos biográficos (Rouleau, 2010). A opção que se faz aqui - e que justifica também as escolhas metodológicas específicas - é por um paradigma narrativo, em que se pode compreender a construção social da estratégia, sob a perspectiva da prática (Fenton \& Langley, 2011), dado por que se entende que a "forma narrativa é constitutiva da compreensão humana e é fundamental na construção de sentido, construção de identidade e ação propositada" (O’Connor, 2002, p. 36, tradução nossa).

Os dados foram coletados a partir de entrevistas narrativas, as quais "[têm] em vista uma situação que encoraje e estimule um entrevistado ... a contar a história sobre algum acontecimento importante de sua vida e do contexto social" (Bauer \& Gaskell, 2015, p. 93). Assim, a unidade social de análise escolhida para esta pesquisa é uma organização do terceiro setor, criada em 2008, na cidade de Curitiba/PR, e que vem tendo destaque nacional (conquistou prêmios como Empreendedor Social do Futuro - Folha de São Paulo, em 2013, e Prêmio Jovens Inspiradores - Veja, em 2014) por conta de sua forma inovadora de conduzir o trabalho e pelo impacto social que tem alcançado. A história das pessoas e da organização, bem como a história que envolve a criação da estratégia organizacional e sua metodologia de trabalho, foram os motes narrativos para as entrevistas. Foram coletados também documentos cujas narrativas são expressas de forma verbal e formal, bem como artefatos que carregam significados e são peças-chave para a compreensão daqueles significados que aparecem nas histórias. A observação não participante de episódios organizacionais também foi utilizada, com o objetivo de observar os movimentos discursivo-narrativos nos momentos de interação social. A coleta de dados deuse entre os meses de outubro/2014 e fevereiro/2015, com imersão profunda no campo de pesquisa. A abordagem naturalística (Given, 2008) adotada para a condução da observação permitiu um acesso fidedigno do contexto de pesquisa, evidenciando como as ações dos participantes efetivamente ocorrem no cotidiano. $\mathrm{O}$ acesso amplo e a imersão profunda do pesquisador no campo deram-se, primeiramente, pela aceitação incondicional da pesquisa. Essa aceitação está alicerçada em dois pontos: (a) o vínculo com o ambiente acadêmico que os empreendedores possuem; (b) a natureza colaborativa da organização em questão, que assenta sua gestão em um colegiado formado por professores, pesquisadores, empresários, entre outros. Assim, aceitar o pesquisador como observador deu-se de maneira ampla e irrestrita, permitindo o acompanhamento do cotidiano e dos eventos organizacionais. Dado esse acesso, o pesquisador passou a frequentar a organização e a observar, imerso no cotidiano, as ações, as atividades e os eventos (Wilkinson \& Birmingham, 2003) desenvolvidos ordinariamente na organização durante o período da coleta de dados. Foram realizadas 07 entrevistas, contabilizando por volta de 400 minutos de gravações, as quais foram integralmente transcritas para análise. Foram coletados documentos que continham dados secundários relevantes para compor a narrativa organizacional. Além disso, desenvolveu-se observação não participante em eventos relevantes do cotidiano organizacional (como o Café de Boas Práticas, o Voluntariado Corporativo, eventos promovidos pela organização 
e reuniões estratégico-administrativas), o que totalizou aproximadamente 960 minutos de observação, registrada por meio de áudio, imagens, quando pertinentes, e diário de campo.

Destaca-se que a análise de narrativas se apoia em cinco pontos fundamentais correspondentes à estrutura da narrativa: (a) a sequência temporal; (b) os atores focais ou o ator focal; (c) a voz narrativa; (d) padrões de referência para avaliação; (e) outros indicadores de conteúdo e contexto (Pentland, 1999).

Não obstante, a Tipologia das Narrativas Empreendedoras, propostas por O'Connor (2002, p. 41), mostra-se como um caminho metodológico útil para esta pesquisa, dado que o empreendimento social em estudo se aproxima das características empreendedoras discutidas por O'Connor (2002) em sua pesquisa. Na Tipologia, O'Connor (2002) trabalha com três tipos de categorias de narrativas, as quais foram adaptadas para esta pesquisa e sistematizadas no quadro da Tabela 1, a seguir:

Tabela 1

\section{Tipologia das Narrativas Empreendedoras}

\section{Histórias Pessoais}

Produzidas pelos diversos praticantes da estratégia

\section{A. Histórias sobre a fundação}

São autobiográficas em natureza ("Porque eu fundei...”). Podem referir-se a incidentes específicos na vida dos fundadores. São evocadas pelos demais participantes em suas narrativas sobre o fazer estratégia e imbricam-se com suas histórias pessoais.

\section{B. Histórias visionárias}

Focam na inovação social como vislumbrada pelos fundadores. São evocadas pelos demais participantes em suas narrativas sobre o fazer estratégia, os quais apresentam em suas falas elementos compartilhados dessa visão.

\section{Histórias Genéricas}

Modelos, requeridos por documentos convencionais, como planos de negócios, modelos de negócio, planos estratégicos etc.

\section{A. Histórias de Marketing}

Apresentadas como as formas de vender a ideia do negócio, tanto para investidores quanto para os atendidos pela proposta do negócio.

\section{B. Histórias da estratégia}

Estão relacionadas ao sensegiving, à forma como a organização traduz a sua estratégia, o seu projeto de negócio para os seus diversos praticantes.

\section{Histórias Situacionais}

Histórias contextuais sobre as quais os fundadores não têm controle, mas que são fundamentais para o delineamento e a história do negócio.

\section{A. Histórias históricas}

São os eventos históricos que dão espaço para o surgimento do negócio, como, por exemplo, surgimento de leis, restrições de recursos etc.

\section{B. Histórias convencionais}

Aqui estão as grandes narrativas do campo de negócios ou do setor de atuação, que revelam as crenças compartilhadas, as práticas sociais que se relacionam ao campo de atuação do negócio.

Nota. Fonte: Adaptada para este contexto de pesquisa de O'Connor, E. (2002). Storied business: tipology, intertextuality, and traffic in entrepreneurial narrative (p. 41, tradução nossa). The Journal of Business Communication, 39(1), 36-54. http://dx.doi.org/10.1177/002194360203900103

Ao trabalhar as narrativas a partir da tipologia anteriormente descrita, pode-se estabelecer a ligação entre os níveis micro (relacionado às Histórias Pessoais dos envolvidos no fazer estratégia, permitindo-se trabalhar a categoria dos praticantes), micro-meso (relacionado às Histórias Genéricas, que se referem às práxis, aos textos da estratégia, ao processo de sensegiving e sensemaking a respeito da estratégia organizacional) e macro (relacionado às Histórias Situacionais, que se referem às práticas 
relacionadas à estratégia). A identificação de cada uma dessas categorias narrativas dá-se a partir do processo operacional, que é descrito a seguir, na Figura 2.

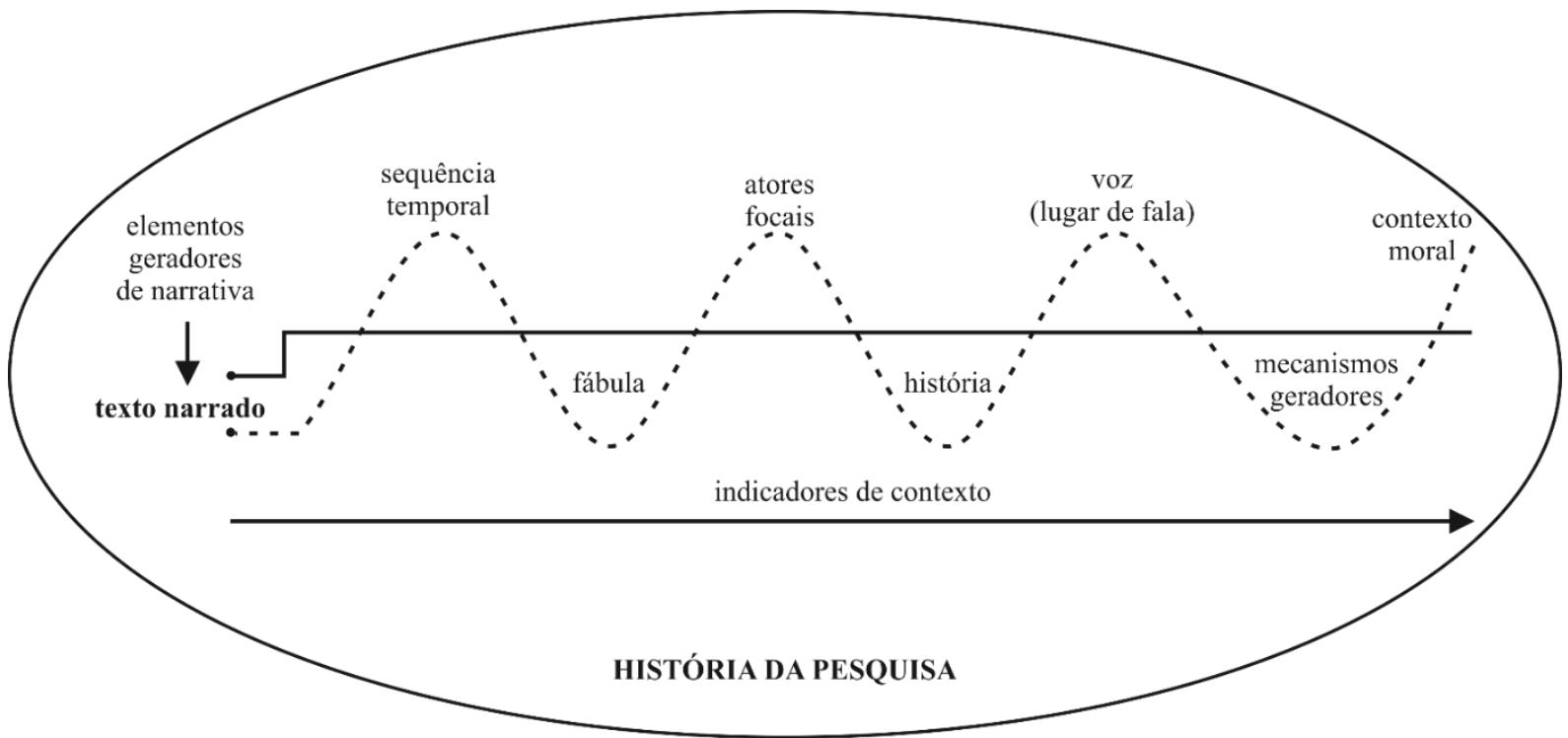

Figura 2. Processo de Análise

Fonte: Adaptada de Kuabara, F. H. (2015). A tradução e a interpretação da estratégia em um negócio social: um estudo de caso sob a perspectiva das práticas sociais (Dissertação de mestrado). Universidade Federal do Paraná, Curitiba, PR, Brasil.

$\mathrm{Na}$ operacionalização desta análise, intencionando alcançar as ligações entre estruturas superficiais e internas das narrativas, partiu-se da construção de mapas mentais em que se organizaram as narrativas e identificaram-se as tipologias supracitadas. Assim, para a costura dessa análise, foi elaborado o plano de análise, conforme a Figura 2.

Ao desenvolver essa trajetória, foi possível categorizar, a partir da tipologia proposta na Tabela 1 , as narrativas, e construir a história da pesquisa, podendo-se compreender o processo de strategizing de forma ampla e responder ao objetivo de pesquisa.

Observa-se que, apesar desse "tipo de estudos narrativos serem particularmente difíceis de serem conduzidos por causa das limitações de tempo e de necessitarem de um acesso extensivo e confiança" (O'Connor, 2002, p. 36, tradução nossa), essa pesquisa teve um acesso profundo ao caso analisado e uma imersão intensa de 5 meses de coleta de dados, o que resultou em uma riqueza narrativa, conforme se observa na Tabela 2 a seguir: 
Tabela 2

Quadro Resumo da Relação entre Dado, Narrativa e Conteúdo Apreendido

\begin{tabular}{|c|c|c|c|c|}
\hline $\begin{array}{l}\text { Tipo de } \\
\text { Dado }\end{array}$ & Coleta & Narrativa Captada & $\begin{array}{l}\text { Categoria } \\
\text { Analisada }\end{array}$ & Conteúdo \\
\hline $\begin{array}{l}\text { Entrevista } \\
\text { Narrativa }\end{array}$ & $\begin{array}{l}07 \text { entrevistas com: } \\
\text { fundadores, principais } \\
\text { colaboradores da } \\
\text { organização, investidores e } \\
\text { público atendido pelo } \\
\text { serviço prestado pela } \\
\text { organização. }\end{array}$ & $\begin{array}{l}\text { Histórias pessoais } \\
\text { Histórias genéricas } \\
\text { Histórias situacionais }\end{array}$ & $\begin{array}{l}\text { Praticantes } \\
\text { / Práticas / } \\
\text { Textos da } \\
\text { Estratégia }\end{array}$ & $\begin{array}{l}\text { A narrativa é desenvolvida pelos } \\
\text { sujeitos de forma a articular } \\
\text { plausivelmente o seu entendimento a } \\
\text { respeito de história, trajetória, } \\
\text { estratégia e resultados. É um } \\
\text { momento valioso de sensegiving e } \\
\text { sensemaking. }\end{array}$ \\
\hline Observação & Café de Boas Práticas. & $\begin{array}{l}\text { Histórias pessoais } \\
\text { Histórias genéricas } \\
\text { Histórias situacionais }\end{array}$ & $\begin{array}{l}\text { Textos da } \\
\text { Estratégia / } \\
\text { Práticas / } \\
\text { Práxis }\end{array}$ & $\begin{array}{l}\text { Conversas em torno das grandes } \\
\text { narrativas do mundo dos negócios a } \\
\text { serem difundidas entre todos os } \\
\text { praticantes. É um momento valioso de } \\
\text { sensegiving e sensemaking. }\end{array}$ \\
\hline Observação & $\begin{array}{l}\text { Voluntariado Corporativo } \\
\text { - Mão na Massa. }\end{array}$ & $\begin{array}{l}\text { Histórias pessoais } \\
\text { Histórias genéricas }\end{array}$ & Práxis & $\begin{array}{l}\text { Conversas em torno da causa e } \\
\text { difusão dela para os investidores. É } \\
\text { um momento valioso de sensemaking. }\end{array}$ \\
\hline Observação & $\begin{array}{l}\text { Premiação Melhores do } \\
\text { IDEE. }\end{array}$ & $\begin{array}{l}\text { Histórias pessoais } \\
\text { Histórias genéricas }\end{array}$ & $\begin{array}{l}\text { Textos da } \\
\text { Estratégia / } \\
\text { Práticas }\end{array}$ & $\begin{array}{l}\text { Formalização discursiva e material do } \\
\text { enquadramento dos praticantes às } \\
\text { grandes narrativas do campo dos } \\
\text { negócios. É um momento valioso de } \\
\text { sensegiving. }\end{array}$ \\
\hline Observação & $\begin{array}{l}\text { Reunião de } \\
\text { acompanhamento da } \\
\text { Assessoria Administrativa. }\end{array}$ & $\begin{array}{l}\text { Histórias pessoais } \\
\text { Histórias genéricas } \\
\text { Histórias situacionais }\end{array}$ & $\begin{array}{l}\text { Textos da } \\
\text { Estratégia / } \\
\text { Práticas / } \\
\text { Práxis }\end{array}$ & $\begin{array}{l}\text { Conversas sobre as atividades } \\
\text { cotidianas em torno do fazer } \\
\text { estratégia, na qual as narrativas sobre } \\
\text { a práxis aparecem. }\end{array}$ \\
\hline Documentos & $\begin{array}{l}\text { Modelo de Negócios; } \\
\text { Planejamento Estratégico; } \\
\text { Relatórios Corporativos; } \\
\text { Materiais de Divulgação, } \\
\text { Promoção e Marketing. }\end{array}$ & $\begin{array}{l}\text { Histórias pessoais } \\
\text { Histórias genéricas } \\
\text { Histórias situacionais }\end{array}$ & $\begin{array}{l}\text { Textos da } \\
\text { Estratégia / } \\
\text { Práticas }\end{array}$ & $\begin{array}{l}\text { Materialização da estratégia em } \\
\text { textos, carregada de elementos de } \\
\text { sensegiving, das grandes narrativas do } \\
\text { campo da estratégia, das práticas do } \\
\text { campo. }\end{array}$ \\
\hline
\end{tabular}

Nota. Fonte: Elaborada pelos autores.

Salienta-se que todos esses procedimentos culminam em uma narrativa de pesquisa, resultado das idas e vindas dos pesquisadores ao campo, da análise sistemática dos dados e também da orientação teórica que auxilia os pesquisadores na análise dos dados.

\section{Descrição da Unidade Social de Análise e Análise dos Dados - Contando e Interpretando a História}

E tudo começou na Universidade, espaço carinhosamente chamado por nossos personagens de federal. É nesse espaço - e tempo, ano de 2008 - que se dá o encontro dos personagens dessa história, os sócios-fundadores da organização Empreendendo um Sonho (nome fictício atribuído à organização em análise). Os personagens principais, fundadores da organização, são: (a) Aristóteles - Diretor de Projetos; (b) Platão - Diretor de Voluntariado; (c) Heráclito - Diretor Comercial. Aristóteles, possui esse codinome na pesquisa como uma analogia ao filósofo grego, pai da lógica, pensador influente na educação, nas ciências humanas, que valorizava a dimensão humana e foi o formador de muitos discípulos influentes na história mundial. O Aristóteles dessa narrativa é o articulador da ideia do 
negócio em questão, aquele que forma (e inspira os demais membros), que mantém viva a crença na ação humana como forma de transformar o mundo. O Platão aqui representado é assim chamado por conseguir separar de forma mais clara o sensível do visível, assim como filosofou aquele que lhe empresta o nome. Heráclito, por sua vez, é aquele que vive a luta dos contrários na sua atividade cotidiana, e está sob a pressão de duas lógicas divergentes: a da causa e a do negócio; assim, está em permanente fluxo de mudança, alinhado com as ideias do seu homônimo grego. Aristóteles, Platão e Heráclito - nesta história - conviveram em um espaço comum durante o período em que cursavam graduação (diferentes cursos) na Universidade Federal do Paraná: a Empresa Júnior do Setor de Ciências Sociais Aplicadas.

Apresentados os personagens principais, iniciou-se uma nova jornada para que a ideia do empreendimento fosse viabilizada. E qual era essa ideia? A organização Empreendendo um Sonho define-se como

uma organização sem fins lucrativos que trabalha desde 2010 para desenvolver uma gestão qualificada para Escolas e Centros de Atendimento filantrópicos para a pessoa com deficiência, atendendo de maneira gratuita estas instituições... Desde o início das atividades a forma de atuação foi aprimorada, passando a realizar além de Assessorias Administrativas, Programas de Voluntariado Corporativo e criação de Redes e Alianças em prol das instituições (Empreendendo um Sonho, 2015, p. 8).

Recém-formados em Administração e Economia, os empreendedores entendiam que era necessário planejar muito bem o conceito do negócio e a estratégia a ser seguida, ideia esta que é fruto da formação dos três personagens (Jarzabkowski \& Wilson, 2006). Nesse contexto, entende-se que a formação profissional e seus aspectos normativos permitem a compreensão da estratégia como prática social na dimensão de análise da ação empreendedora desses três sujeitos. A estratégia do negócio em questão, portanto, é uma produção desses profissionais, com base nas regras e recursos (Giddens, 2003) aprendidos em um contexto de formação profissional universitário e que fazem parte do arcabouço constitutivo da profissão, voltada para o contexto do empreendimento novo, situado e único, mas conectado com o que se entende como o modus operandi de fazer negócios. Os fundadores estão, portanto, imersos no contexto das grandes narrativas da estratégia - que se manifestam nas Histórias Pessoais, Genéricas e Situacionais (O'Connor, 2002) - e tornam-se portadores das práticas sociais relacionadas a tais narrativas (La Ville \& Monoud, 2003, 2010). Esses sujeitos reflexivos e cognoscitivos são os produtores e reprodutores dessa estrutura formal do que é fazer negócio, mas, em sua ação, também são capazes de significar e ressignificar as estratégias em novos contextos.

Com base no entendimento construído a respeito do negócio na fase narrada, a busca por parceiros investidores levou quase todo o ano de 2009, e Aristóteles narra uma passagem representativa de um anticlímax em que, diante de inúmeras negativas na busca por parceiros, os empreendedores viam-se desestimulados e prestes a desistir. Nesse momento, já formados, com uma ocupação como empreendedores que não resultava em retorno financeiro, com a reprovação da continuidade das atividades dentro do grupo social de convívio desses sujeitos e diante da desistência iminente, acontece uma reviravolta na história, a qual dá todo o tom da narrativa que se segue:

\footnotetext{
"E aí a gente viu que a empresa não iria investir na gente pura e simplesmente por caridade. As empresas queriam um retorno sobre isso. Que fosse um marketing, que fossem outras coisas. Daí a gente começou uma reunião depois da outra, recebendo muitos feedbacks do que a gente poderia melhorar, uns feedbacks pesados, né. E, a cada reunião, a gente ia se estruturando mais. E então a gente reestruturou propostas de retorno de marketing, trabalhos por cota, mas nada disso estava funcionando. Estava faltando alguma coisa. Até a hora que veio o estalo: A gente tem que envolver os colaboradores das empresas com esses projetos. Como que a gente vai fazer isso? Com o voluntariado corporativo" (Platão).
}

Em um momento de crise como o que passava a Empreendendo um Sonho, é natural que um processo de ressignificação da breve trajetória entre em cena. Nesse processo de ressignificação, o sensemaking do próprio foco do negócio ocorre e, ao compreender o objeto final como sendo a assessoria para escolas de educação especial oferecida de forma gratuita, sendo que esse trabalho precisaria ser financiado de alguma forma, os empreendedores começam a compreender que precisavam 
falar a mesma língua que os seus financiadores pretendidos. Nesse momento, o negócio começa a ser reestruturado como uma rede, pautada em alianças estratégicas. Dessa rede, fazem parte como ator central a Empreendendo um Sonho, as empresas que financiam os projetos, bem como as escolas atendidas. Ao falar a língua do mundo dos negócios, ao invés da língua da causa, com os potenciais parceiros financiadores, a organização consegue fechar sua primeira parceria e desenvolver seu primeiro projeto. Começa, assim, uma sucessão de episódios de novos projetos, crescimento e aquilo que pode ser caracterizado como sucesso, em relação ao objetivo inicialmente traçado.

Descoberta a fórmula para o sucesso, a lógica dos negócios começa a prevalecer na forma de desenvolver o trabalho, potencializando cada vez mais os apoiadores da ideia. Ao racionalizar esse processo e explicitá-lo no documento Relatório de Impacto 2013, desenvolvido pela organização, Aristóteles, Platão e Heráclito assinam uma narrativa que assume a lógica de negócios, destacando a metodologia que embasa o desenvolvimento do empreendimento e o foco em resultados como o atestado do sucesso organizacional:

Passamos todo o ano de 2009 estudando o meio e conhecendo mais a fundo a realidade da pessoa com deficiência através da leitura de materiais e visitas a instituições de atendimento especializado de cunho privado e gratuito, de Curitiba e Região. Com as informações adquiridas, formatamos uma metodologia de atuação. No mesmo período, próximo ao final do ano e já preparados para o primeiro projeto, tomamos conhecimento de uma Escola de grande impacto social que estava passando por uma situação crítica, inclusive com risco de fechamento (Empreendendo um Sonho, 2013, p. 3).

A metodologia de trabalho da organização está baseada em uma série de artefatos visuais e textuais que facilitam os processos de sensegiving e sensemaking a respeito da proposta do negócio entre os seus praticantes e os contextos de atuação. Essa metodologia busca estabelecer desde o planejamento, até a estruturação organizacional, passando pela captação de recursos e o monitoramento de resultados das organizações atendidas pela Empreendendo um Sonho. Em termos formais, a metodologia possui 5 fases a saber: (a) seleção, (b) diagnóstico (baseado na aplicação do Índice de Desenvolvimento da Educação Especial (IDEE), ferramenta desenvolvida pela organização), (c) planejamento, (d) execução (fases em que são aplicadas as diversas ferramentas do campo da estratégia) e, (e) aplicação do IDEE (fase em que novamente o Índice desenvolvido pela Empreendendo um Sonho é aplicado como forma de avaliar os resultados alcançados).

Percebe-se que a racionalidade formal que embasa o desenvolvimento da administração moderna está presente na metodologia explicitada pela Empreendendo um Sonho. É possível perceber nesse segundo momento narrativo um aspecto relevante: o empreendimento só começou a se desenvolver a partir do momento em que os empreendedores passaram a encadear discursivamente (Hardy \& Thomas, 2014) as regras e os recursos inerentes às práticas sociais do campo dos negócios corporativos em um processo de sensegiving, em que os personagens centrais da trama "tentam atribuir sentido a fim de influenciar outras pessoas a perceber e a interpretar certas ações e eventos de um jeito particular" (Søderberg, 2003, p. 7, tradução nossa), e assim engajarem-se na ideia do negócio. Relevante ainda destacar o papel relevante da linguagem (Mantere, 2013; Oliveira \& Bulgacov, 2013) no processo. Mantere (2013, p. 1414) articula uma "abordagem baseada na linguagem" da estratégia, defendendo o argumento de que a estratégia é um jogo de linguagem (Wittgenstein, 2000) jogado pelos praticantes na organização, variando entre organizações, mas conectados por "rótulos produzidos pela 'indústria da administração estratégica"” (Mantere, 2013, p. 1415, tradução nossa). Conectar-se, portanto, a esses macro discursos do campo dos negócios, permitiu o engajamento em um micro jogo de linguagem que possibilitou a construção do sentido a respeito da estratégia organizacional para os principais investidores do negócio (La Ville \& Monoud, 2003, 2006, 2010). Observa-se que a conexão com os macro discursos e a estratégia em ação, como uma prática social do campo, foi suficiente para balizar as regras do jogo de linguagem necessário para que o entendimento e a negociação entre os atores acontecesse.

Se Aristóteles, Platão e Heráclito descobriram que, para obter sucesso nas parcerias que financiam seu negócio principal, precisariam conversar no mesmo idioma do mundo dos negócios que seus 
investidores falavam, ou seja, fazer uso da linguagem, da lógica e das ferramentas que aprenderam no curso de administração, evidenciando o caráter de prática social da estratégia no mundo das organizações empresariais, agora enfrentariam um novo desafio: como traduzir e facilitar a interpretação da sua estratégia organizacional no contexto das escolas, onde a lógica da causa prevalece? Contrariamente ao contexto dos investidores, o contexto das escolas atendidas não significa a estratégia organizacional como uma prática social. Evidência disso é o princípio gerador do negócio da Empreendendo um Sonho: a falta de eficiência na gestão ocasiona problemas no funcionamento dessas escolas, o que faz com que tenham uma atuação aquém do esperado e do necessário para o atendimento ampliado de pessoas com necessidades especiais.

Entram em cena nesta narrativa novos personagens, que unem suas vozes a este texto de forma a possibilitar a compreensão de como se dá esse processo. O primeiro personagem a ser mencionado será chamado de Alexandre, o principal discípulo de Aristóteles, que leva as ideias desse ao contexto das escolas: Alexandre trabalha como Analista de Projetos na Empreendendo um Sonho. A segunda personagem que vem à cena será chamada de Helena, Diretora de uma Escola atendida pela organização, líder em um território desconhecido.

A base da atividade organizacional da Empreendendo um Sonho consiste em potencializar o desenvolvimento de escolas que atendam pessoas com deficiência. Para esse fim, o primeiro passo refere-se à seleção de organizações que possam ser atendidas a partir do critério de necessidade, urgência e impacto. A partir disso, fechado o aceite de parceria entre as duas partes - Empreendendo um Sonho e escola - inicia-se um processo sistemático de diagnóstico, planejamento, execução e avaliação de resultados, pautados em ferramentas específicas. Destaca-se o papel do IDEE - Índice de Desenvolvimento da Educação Especial - criado pela organização, e que é usado em dois momentos: no diagnóstico e na mensuração de resultados, além de ser a base para demonstração de resultados para investidores e também a base de premiação e reconhecimento dos melhores resultados em eventos de premiação. Na fase de implementação, entram em cena outros eventos importantes relacionados ao voluntariado, com atores vindos das empresas parceiras, que ajudam a viabilizar as necessidades das Escolas, objetos dos projetos.

O ponto de destaque do processo de assessoria é que, ao selecionar as Escolas que serão atendidas, o papel que se espera da Empreendendo um Sonho é assistencial, no entanto, não é isso que ocorre. A organização propõe a reestruturação administrativa, e promover essa significação é um processo de constante construção:

\footnotetext{
“Às vezes você vai, faz a ferramenta e ensina a usar, e a instituição não incorpora aquilo. Hoje a gente tem uma taxa de acerto muito maior. Mas no início a gente falhava bastante nesse processo de querer impor um determinado conhecimento, uma determinada prática. Então a gente percebe que é um passo a passo mesmo. Primeiro você mostra você ensina, você repete até que isso se incorpora. E às vezes não é imediato.... Então, às vezes é um processo de amadurecimento mesmo assim. De quase um convencimento de uma venda de um produto, você vai pouco a pouco até que a pessoa se conscientiza da necessidade" (Alexandre).
}

Quando Alexandre conta como se dá o processo de construção, começa-se a perceber alguns movimentos de resistência. Entende-se que a realização da estratégia da Empreendendo um Sonho depende da integração entre os diferentes praticantes e da interpretação de cada um deles a respeito dessa estratégia. Se de um lado os financiadores - por compartilharem regras e recursos de um mesmo campo organizacional, em que os micro jogos são consonantes com os macro discursos - jogam o mesmo jogo de linguagem da Empreendendo um Sonho, por outro, as escolas atendidas não compartilham das mesmas regras do jogo e jogar o mesmo jogo de linguagem não é um processo natural para elas. Ao tentar promover o processo de sensegiving com as escolas, observa-se que o sensemaking esbarra na linguagem não compartilhada, dado que nesse contexto a estratégia não pode ser assumida como uma prática social, pois ela não é representada como "tipos rotinizados de comportamento" (Reckwitz, 2002, p. 249, tradução nossa), que os sujeitos fazem uso em uma atividade de strategizing. Essa atividade é desconhecida, as regras e os recursos não são compartilhados. Assim, inicia-se um processo de escrita e leitura (La Ville \& Monoud, 2003, 2006, 2010) da estratégia nesse 
contexto, e novas regras desses jogos de linguagem que se iniciam precisam ser negociadas e construídas.

Helena conta que, no primeiro contato com a Empreendendo um Sonho, "[eles] vieram, fizeram o diagnóstico ..., colocaram tudo isso em um projeto" (Helena). Helena ainda ressalta o papel importante que as ferramentas, como artefatos da atividade de organizar e artefatos visuais, desempenham nesse processo:

"que nem essa questão aí do projeto, por exemplo, muitas ferramentas, muitas dicas, muitas instruções, eles vêm aqui, falam e dão assim, da maneira que eles colocam a gente sente vontade de fazer mesmo, tipo assim, a gente se sente capaz.... E de tudo é sempre muito bem colocado, muito bem explicado, em relação a projetos, em relação às ações que a gente tem que fazer, em tudo assim. Eles sempre têm uma ferramenta, sempre têm uma coisa muito legal para passar pra gente, que a gente sente vontade de fazer" (Helena).

Esse processo, no entanto, não é passivo e natural. Platão evidencia em sua fala que a construção de significado do que é o conteúdo estratégico da Empreendendo um Sonho é um processo constante:

"É um processo de alinhamento de expectativa. Já teve escola que veio até aqui querendo simplesmente uma reforma. Então elas veem a gente como um facilitador para conseguir recursos para alguma ação. Mas não é assim e aí a gente tem que explicar: Ó, o nosso trabalho funciona da seguinte forma, a gente faz um diagnóstico lá na instituição de vocês, desenvolve um projeto para melhorar a gestão, porque a gente sabe que através da gestão, no longo prazo, vocês vão poder gerar mais impacto social.... E dependendo da vontade do investidor e da necessidade de vocês, aí sim, a gente vai fazer alguma ação de infraestrutura" (Platão).

Existem elementos, também, que garantem legitimidade à atuação organizacional e, assim, contribuem com a possibilidade de construção de significado a respeito da estratégia da Empreendendo um Sonho junto aos seus parceiros:

“E elas se questionam, 'Quem é que esse pessoal?' ‘Por que é que eles estão fazendo isso?' E daí elas ficam sabendo, 'nossa eles já fizeram isso aqui em tal escola, isso aqui naquela outra.'; 'Olha, os investidores que eles têm. São empresas muito grandes'. 'Eles têm uma campanha que está em 50 lugares' 'Já ganharam tais prêmios'. 'O trabalho deles é bom'. Então elas ligam” (Platão).

Alexandre é capaz de descrever o processo que acontece, com um jeito simples, mas que evidencia a complexidade do que ocorre: "Então a gente percebe que é um passo a passo mesmo. Primeiro você mostra, você ensina, você repete, até que isso se incorpora. E às vezes não é imediato" (Alexandre). Ao apresentar o processo nesses termos, Alexandre evidencia a fase da escrita (Primeiro você mostra, você ensina), da leitura (você repete, já que essa leitura não é passiva e a escrita precisa ser significada) e da assimilação de uma nova prática social (até que isso se incorpora).

Dessa forma, em consonância com o que é apresentado por La Ville e Monoud (2003, 2006, 2010) percebe-se que a estratégia se torna uma prática social em um contexto a partir do momento em que as regras e os recursos a ela atrelados passam a orientar as atividades cotidianas nas organizações escolares. Esse processo se dá de acordo com a representação da Figura 3: 


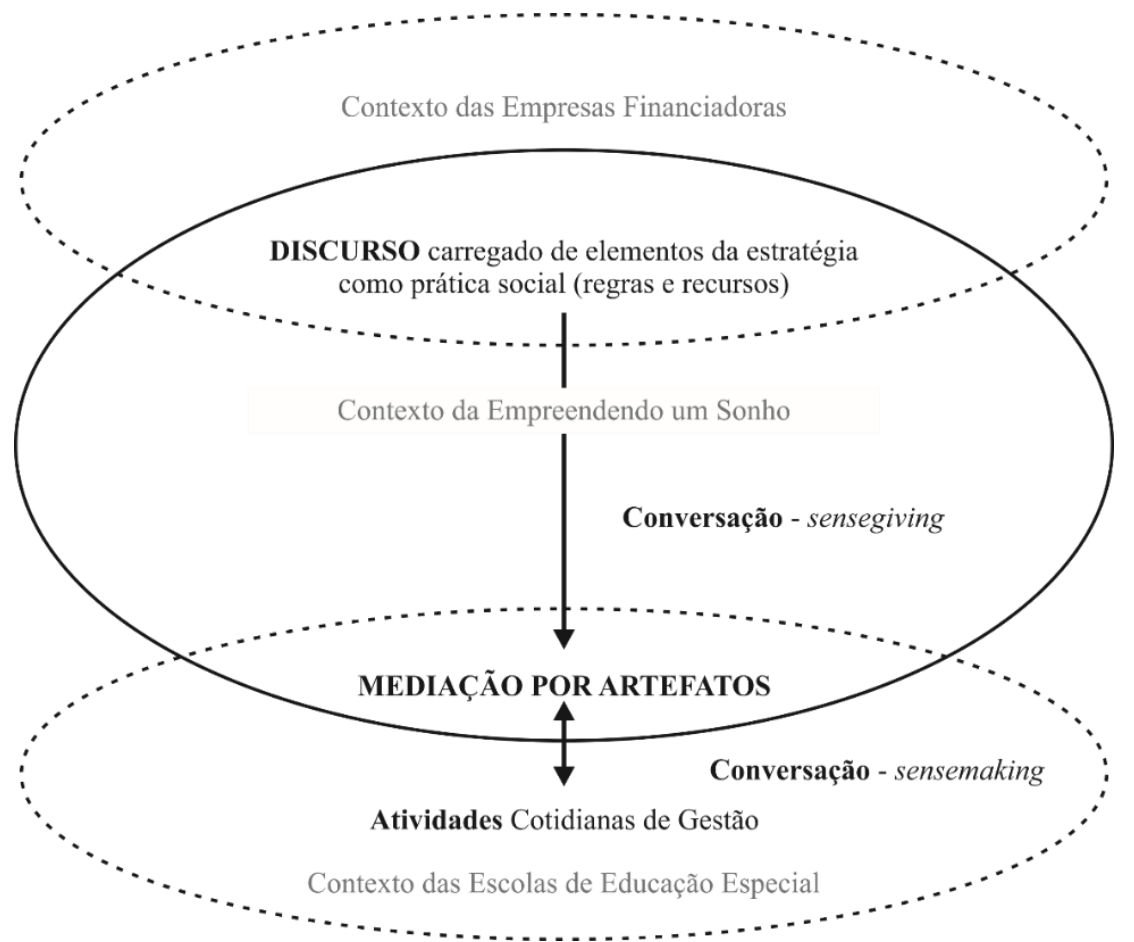

Figura 3. O Processo de Construção da Estratégia como uma Prática Social Fonte: Elaborada pelos autores.

Desse processo podem ser depreendidos resultados de pesquisa relevantes. Primeiramente, com base na Figura 3, pode-se entender que o negócio da Empreendendo um Sonho localiza-se entre dois mundos distintos: aquele dos investidores (parte superior), carregado de práticas sociais compartilhadas do mundo corporativo e aquele do público-alvo (parte inferior) das ações organizacionais da Empreendendo um Sonho, em que estão as Escolas de Educação Especial, carregadas do propósito da causa. A conversa com esses dois mundos não é a mesma. As atividades de práxis cotidianas e as práticas sociais também diferem fundamentalmente. Mas é no papel dos praticantes da estratégia, articuladores de sentido, que os dois mundos se encontram. Desse movimento, três resultados principais devem ser destacados: (a) a narrativa desenvolvida na conversação com os investidores é carregada de histórias situacionais e articulam elementos das grandes narrativas da estratégia, objetivando um convencimento para o investimento; (b) a narrativa desenvolvida na conversação com o público atendido (Escolas de Educação Especial) é carregada de histórias genéricas - em que se articulam textos e artefatos - no fazer cotidiano de práxis situadas; (c) o sentido dado (sensegiving) pelos estrategistas da Empreendendo um Sonho e construído (sensemaking) pelos diferentes praticantes (estrategistas, investidores e atendidos) em um processo narrativo de negociação de significado, cuja legitimidade está assentada nas histórias pessoais e cuja plausibilidade nas histórias genéricas (atendidos) e situacionais (investidores).

Na dinâmica referente ao primeiro resultado, observa-se que a práxis envolvida está relacionada a atividades de apresentação de propostas, negociações, demonstração do binômio investimento e retorno, que ocorrem em episódios específicos de reuniões entre duas categorias de praticantes da estratégia da Empreendendo um Sonho: os estrategistas da organização e os investidores. Recorrem-se a práticas sociais da estratégia como reuniões, relatórios de resultado, planos e demonstrativos. Em torno dessas práticas e da práxis cotidiana, os praticantes desenvolvem textos da estratégia - em sua dimensão discursiva, ao argumentarem, apresentarem, mas também em sua dimensão material, ao fazer uso de artefatos textuais e visuais que conferem materialidade à fala - com o objetivo de dar sentido (sensegiving) a respeito de sua proposta e obter o investimento ao final. Esse movimento surge principalmente nas histórias situacionais, em que se chamam os elementos históricos (dados, leis, tendências de mercado) e convencionais (ideias sobre a responsabilidade social, de retorno do investimento, impacto social do negócio). O caso analisado permite compreender que é a partir do 
conhecimento das regras desse jogo de linguagem que os resultados de fechamento de parcerias começam a aparecer.

Além disso, na conversação com o público atendido, há um movimento ativo de influenciação de sentido (sensegiving) a respeito da estratégia da Empreendendo um Sonho, bem como das atividades necessárias para que ela se realize. Ocorre também um processo de negociação de significados e construção de sentido (sensegiving) entre todos os atores, uma vez que a novidade do que a Empreendendo um Sonho propõe torna a compreensão do que ela oferece uma tarefa complexa. Assim, são empreendidas práxis cotidianas em torno de diagnósticos, desenvolvimento de procedimentos de trabalho, de planejamento, de controles e resultados, com base nas práticas sociais do mundo da estratégia, como os planos e os indicadores estratégicos e suas metodologias características. O processo de criação dos textos ocorre com o objetivo de traduzir as grandes narrativas da estratégia para esse novo contexto. Esse movimento pode ser visto principalmente na articulação de histórias genéricas, em que são apresentadas as propostas do negócio, suas ideias e suas formas de atuação, e das histórias da estratégia em que o projeto do negócio é apresentado discursivamente nos diversos encontros de práxis e materializado em metodologias aplicadas para orientação das atividades situadas.

Não obstante, por fim, em relação ao terceiro resultado apontado, é possível perceber que, no processo de negociação de significados, entre sensegiving e sensemaking, observa-se um papel relevante das histórias pessoais (relacionadas às histórias sobre a fundação da Empreendendo um Sonho e às histórias visionárias, focadas na inovação da proposta do negócio em questão), que conferem legitimidade à organização perante os diferentes praticantes. Se perguntados sobre por que investem, ou por que trabalham com a Empreendendo um Sonho, os investidores e os atendidos discorrem longamente sobre as histórias pessoais, relacionadas à fundação motivada pelo sonho de meninos empreendedores que possuem uma ligação íntima com pessoas portadoras de necessidades especiais em suas famílias e também no quão inovadores e corajosos os meninos são. Além disso, a plausibilidade da proposta que alicerça o engajamento dos diferentes praticantes está assentada nas histórias genéricas (com relação aos atendidos) e nas histórias situacionais (com relação aos investidores), reforçando o argumento de que o fazer estratégia está alicerçado na articulação da linguagem e no jogo narrativo que se estabelece entre os praticantes.

Para finalizar, o movimento de tradução da estratégia como prática social para um novo contexto, conforme se propôs como objetivo desta pesquisa, dá-se na medida em que há essa articulação entre as diferentes histórias. A ênfase nas práticas sociais da estratégia - que vão balizar toda a conversação com o público atendido (Escolas de Educação Especial) - vem das regras estabelecidas no jogo de linguagem com os investidores: eles investem porque veem resultado, e esse resultado pode ser visualizado se as escolas atendidas são capazes de implementar, monitorar e mensurar adequadamente seu desempenho, respondendo às demandas do negócio e, consequentemente, levando a cabo a estratégia organizacional proposta pela Empreendendo um Sonho.

Como desdobramentos desses resultados, percebe-se que os estrategistas assumem um papel fundamental como storytellers (corroborando com os achados de Boje, 1991; Samra-Fredericks, 2003), responsáveis por articular discursos legítimos e plausíveis na tradução da estratégia. A competência em articular as grandes narrativas e suas práticas sociais associadas em um fluxo de práxis encadeadas, respaldadas no envolvimento dos diferentes praticantes com a legitimidade das narrativas pessoais, mostra-se como relevante na tradução e na difusão de novas práticas em torno do fazer estratégia. Disso se podem depreender implicações gerenciais importantes: a clareza discursiva e o domínio materialtécnico empoderam os estrategistas na tradução da estratégia e no encorajamento dos praticantes para com seu engajamento.

Faz-se necessário ainda pontuar que, em acordo com La Ville e Monoud (2003, 2006, 2010), percebeu-se que o processo de negociação de sentidos, no sensegiving e sensemaking, não é passivo; há uma negociação ativa, com pontos de resistência e aquiescência, mas cujo resultado é a construção (sensemaking) conjunta dos significados. Esse movimento é identificado pela observação das propriedades narrativas enunciadas por Pentland (1999) e cujo movimento analítico é representado na Figura 2: à medida que as narrativas são vistas a partir da sequência temporal, é possível que os 
movimentos de idas e vindas, resistência e aquiescência, sejam percebidos ao longo do processo narrado; a localização dos atores focais permite também perceber quem se apresenta como protagonista, antagonista e, nessa situação dos personagens, observa-se a posição tomada por cada um no processo de negociação; a voz dos atores e seus padrões de referência demonstram seu lugar de fala, seus posicionamentos e defesas, o que revela incoerências, posições que se mostram em termos de resistência e aquiescência; todos esses pontos são analisados com referência a uma clara definição de conteúdo e contexto da narrativa.

\section{Considerações Finais - Felizes para Sempre?}

Este estudo teve por objetivo compreender como a estratégia torna-se uma prática social, em contextos submetidos a lógicas diversas da lógica capitalista, lócus por excelência da estratégia empresarial e onde ela figura como uma prática social. Identificou-se (endereçando respostas às perguntas de pesquisa específicas que surgiram), pelas narrativas coletadas, que o contexto do mundo dos negócios é o lócus por excelência da estratégia, onde ela figura como uma prática social. Derivado disso, percebeu-se que, em contextos que desafiam a lógica capitalista, como é o caso das Escolas de Educação Especial atendidas pela organização pesquisada e o próprio terceiro setor, onde a Empreendendo um Sonho atua, a estratégia, seus conceitos, práticas, práxis e significados, são desconhecidos e de difícil assimilação, conforme evidenciam os dados narrativos apresentados anteriormente. Observou-se ainda que, para se tornar uma prática, a estratégia precisou ser traduzida em um processo de sensigiving, e os praticantes foram engajados em um processo de sensemaking mediado por textos da estratégia (com dimensões discursiva e material, esta última manifesta em artefatos) carregados das regras e recursos que fazem desta uma prática social. A estratégia torna-se uma prática social, portanto, na medida em que seus significados passam a ser compartilhados nesse novo espaço e, então, passam a orientar as atividades (práxis) cotidianas da estratégia. Em termos de conclusão, portanto, entende-se que, para se tornar uma prática social em um contexto onde não o é, dá-se um exercício qualificado de escrita (sensegiving) e leitura (sensemaking), e que isso só ocorre com sucesso a partir do momento em que são negociadas regras compartilhadas, capazes de balizar o jogo de linguagem (Oliveira \& Bulgacov, 2013). Os textos da estratégia (em sua dimensão discursiva e material) aparecem como os principais mediadores, carregados de aspectos simbólicos, aos quais se atribuem significados mediante as regras compartilhadas do micro jogo de linguagem, conectados ao macro jogo do campo.

Faz-se relevante ainda apresentar uma limitação desta pesquisa. Ao optar pela pesquisa narrativa e circunscrever o objeto de pesquisa à organização Empreendendo um Sonho e os praticantes relacionados à sua estratégia organizacional, pouca atenção foi dada ao contexto institucional do negócio em si. Ainda que a discussão da prática social chame o contexto institucional, neste estudo tal contexto ficou limitado à dimensão macro tratada na perspectiva da estratégia como prática social, sem se estender ao campo do negócio em si. Isso, evidentemente, limitou algumas possibilidades da pesquisa, no entanto, permite sugerir que novos estudos sejam empreendidos de forma a ampliar essa discussão.

Dessa forma, sugere-se como agenda de estudos futuros, resultante dos achados dessa pesquisa, dois pontos fundamentais, dos quais se desdobram problemas específicos: (a) em consonância com Phillips e Oswick (2012), os dados dessa pesquisa demonstram a coconstitutividade das dimensões material e discursiva, o que nos faz sugerir pesquisas que combinem metodologias capazes de dar conta da investigação material e discursiva, como partes do mesmo fenômeno, sendo, portanto, necessária também uma discussão epistemológica consistente com estudos dessa natureza; (b) o processo investigado, a organização objeto deste estudo e as respostas ao objetivo e a perguntas específicas de pesquisa sugerem que sejam empreendidos estudos futuros capazes de compreender o processo de institucionalização de práticas estratégicas em novos contextos, como é o caso das organizações híbridas; o caminho da perspectiva da estratégia como prática nos parece promissor, em consonância com as discussões promovidas por Smets et al. (2015). Por fim, entendemos que os estudos, 
principalmente no Brasil, que endereçarem suas investigações sob a perspectiva da estratégia como prática precisam, necessariamente, empreender metodologias de estudos adequadas ao fenômeno.

\section{Agradecimentos}

Agradecemos ao CNPq pelo apoio por meio do financiamento de projeto de pesquisa ao qual este trabalho está relacionado, Edital de Chamada MCTI/CNPq/MEC/CAPES nº 22/2014.

\section{Referências}

Barry, D., \& Elmes, M. (1997). Strategy retold: toward a narrative view of strategic discourse. Academy of Management Review, 22(2), 429-452. http://dx.doi.org/10.5465/ AMR.1997.9707154065

Battilana, J., \& Dorado, S. (2010). Building sustainable hybrid organizations: the case of commercial microfinance organizations. Academy of Management Journal, 53(6), 1419-1440. http://dx.doi.org/10.5465/AMJ.2010.57318391

Battilana, J., \& Lee, M. (2014). Advancing research on hybrid organizing - insights from the study of social enterprises. The Academy of Management Annals, 8(1), 1-44. http://dx.doi.org/10.1080/19416520.2014.893615

Battilana, J., Sengul, M., Pache, A. C., \& Model, J. (2014). Harnessing productive tensions in hybrid organizations: the case of work integration social enterprises. Academy of Management Journal, 58(6), 1658-1685. http://dx.doi.org/10.5465/AMJ.2013.0903

Bauer, M. W., \& Gaskell, G. (2015). Pesquisa qualitativa com texto, imagem e som: um manual prático (13a ed.). Petrópolis: Editora Vozes.

Berger, P. L., \& Luckmann, T. (2010). A construção social da realidade: tratado de sociologia do conhecimento (14a ed.). Petrópolis: Vozes.

Boje, D. M. (1991). The storytelling organization: a study of story performance in an office-supply firm. Administrative Science Quarterly, 36(1), 106-126. http://dx.doi.org/10.2307/2393432

Boje, D. M., Haley, U. C. V., \& Saylors, R. (2016). Antenarratives of organizational change: the microstoria of Burger King's storytelling in space, time and strategic context. Human Relations, 69(2), 391-418. http://dx.doi.org/10.1177/0018726715585812

Bower, J. L. (2008). The teaching of strategy from general manager to analyst and back again?. Journal of Management Inquiry, 17(4), 269-275. http://dx.doi.org/10.1177/1056492608318149

Brown, A. D., \& Thompson, E. R. (2013). A narrative approach to strategy-as-practice. Business History, 55(7), 1143-1167. http://dx.doi.org/10.1080/00076791.2013.838031

Brown, M. H. (1990). Defining stories in organizations. In J. A. Anderson (Ed.), Communication yearbook, 13 (pp. 162-190). New York: Routledge. http://dx.doi.org/10.1080/23808985.1990.11678752

Chia, R., \& MacKay, B. (2007). Post-processual challenges for the emerging strategy-as-practice perspective: discovering strategy in the logic of practice. Human Relations, 60(1), 217-242. http://dx.doi.org/10.1177/0018726707075291 
Cooren, F. (2001). Translation and articulation in the organization of coalitions: the great whale river case. Communication Theory, 11(2), 178-200. http://dx.doi.org/10.1111/j.14682885.2001.tb00238.x

Czarniawska, B. (1998). A narrative approach to organization studies (Vol. 43). London: Sage. http://dx.doi.org/10.4135/9781412983235

Dobusch, L., \& Kapeller, J. (2013). Open strategy between crowd and community: lessons from wikimedia and creative commons. Academy of Management Proceedings, (1), 15831-15831. http://dx.doi.org/10.5465/AMBPP.2013.15831abstract

Empreendendo um Sonho. (2013). Relatório de impacto empreendendo um sonho 2012 [Relatório]. Curitiba, PR, Brasil.

Empreendendo um Sonho. (2015). Relatório de impacto empreendendo um sonho 2014 [Relatório]. Curitiba, PR, Brasil.

Fenton, C., \& Langley, A. (2011). Strategy as practice and the narrative turn. Organization Studies, 32(9), 1171-1196. http://dx.doi.org/10.1177/0170840611410838

Giddens, A. (2003). A constituição da sociedade. São Paulo: Martins Fontes.

Gioia, D. A., \& Chittipeddi, K. (1991). Sensemaking and sensegiving in strategic change initiation. Strategic Management Journal, 12(6), 433-448. http://dx.doi.org/10.1002/smj.4250120604

Given, L. M. (Ed.). (2008). The Sage encyclopedia of qualitative research methods. Thousand Oaks: Sage Publications. http://dx.doi.org/10.4135/9781412963909

Golsorkhi, D., Rouleau, L., Seidl, D., \& Vaara, E. (Eds.). (2010). Cambridge handbook of strategy as practice. Cambridge: Cambridge University Press. http://dx.doi.org/10.1017/CBO9780511777882

Hansen, H. (2006). The ethnonarrative approach. Human Relations, 59(8), 1049-1075. http://dx.doi.org/10.1177/0018726706068770

Hardy, C., \& Thomas, R. (2014). Strategy, discourse and practice: the intensification of power. Journal of Management Studies, 51(2), 320-348. http://dx.doi.org/10.1111/joms.12005

Holt, R., \& Cornelissen, J. (2014). Sensemaking revisited. Management Learning, 45(5), 525-539. http://dx.doi.org/10.1177/1350507613486422

Jäger, U., \& Beyes, T. (2010). Strategizing in NPOs: a case study on the practice of organizational change between social mission and economic rationale. Voluntas, 21(1), 82-100. http://dx.doi.org/10.1007/s11266-009-9108-x

Jarzabkowski, P. (2004). Strategy as practice: recursiveness, adaptation, and practices-in-use. Organization Studies, 25(4), 529-560. http://dx.doi.org/10.1177/0170840604040675

Jarzabkowski, P. (2005). Strategy as practice: an activity based approach. California: Sage.

Jarzabkowski, P., Balogun, J., \& Seidl, D. (2007). Strategizing: the challenges of a practice perspective. Human Relations, 60(1), 5-27. http://dx.doi.org/10.1177/0018726707075703

Jarzabkowski, P., \& Spee, P. A. (2009). Strategy-as-practice: a review and future directions for the field. International Journal of Management Reviews, 11(1), 69-95. http://dx.doi.org/ 10.1111/j.14682370.2008.00250.x

Jarzabkowski, P., \& Wilson, D. C. (2006). Actionable strategy knowledge: a practice perspective. European Management Journal, 24(5), 348-367. http://dx.doi.org/10.1016/j.emj.2006.05.009 
Johnson, G., Langley, A., Melin, L., \& Whittington, R. (2007). Strategy as practice: research directions and resources. New York: Cambridge.

Jongbloed, B. (2015). Universities as hybrid organizations. International Studies of Management \& Organization, 45(3), 207-225. http://dx.doi.org/10.1080/00208825.2015.1006027

Kuabara, F. H. (2015). A tradução e a interpretação da estratégia em um negócio social: um estudo de caso sob a perspectiva das práticas sociais (Dissertação de mestrado). Universidade Federal do Paraná, Curitiba, PR, Brasil.

La Ville, V. I., \& Mounoud, E. (2003). Between discourse and narration: how can strategy be a practice? In B. Czarniawska \& P. Gagliardi (Eds.), Narratives we organize by (Vol. 11, pp. 95-113). Sweden: John Benjamins Publishing. http://dx.doi.org/10.1075/aios.11.09vil

La Ville, V. I., \& Mounoud, E. (2006). A narrative view on strategizing and organising: the multiple stories of regional, public yet self-designed, organisation. Proceedings of EGOS ColloquiumEuropean Group for Organizational Studies, Bergen, Noruega.

La Ville, V. I., \& Monoud, E. (2010). A narrative approach to strategy as practice: strategy making from texts and narratives. In D. Golsorkhi, L. Roueleau, D. Seidl, \& E. Vaara (Eds.), Cambridge handbook of strategy as practice (pp. 183-197). Cambridge: Cambridge University Press. http://dx.doi.org/10.1017/CBO9780511777882.013

Maitlis, S., \& Christianson, M. (2014). Sensemaking in organizations: taking stock and moving forward. The Academy of Management Annals, 8(1), 57-125. http://dx.doi.org/10.1080/19416520.2014.873177

Mantere, S. (2013). What is organizational strategy? A language-based view. Journal of Management Studies, 50(8), 1408-1426. http://dx.doi.org/10.1111/joms.12048

Meyer, R. E., Höllerer, M. A., Jancsary, D., \& Leeuwen, T. van (2013). The visual dimension in organizing, organization, and organization research: core ideas, current developments, and promising avenues. The Academy of Management Annals, 7(1), 489-555. http://dx.doi.org/10.1080/19416520.2013.781867

Mintzberg, H. (2006). Cinco P`s para estratégia. In H. Mintzberg, J. Lampel, J. B. Quinn, \& S. Ghoshal (Orgs.), O Processo da estratégia (pp. 24-29). São Paulo: Bookman.

Mintzberg, H., Ahlstrand, B., \& Lampel, J. (2000). Safári da estratégia: um roteiro pela selva do planejamento estratégico. Porto Alegre: Bookman.

Nicolini, D. (2012). Practice theory, work \& organization: an introduction. Oxford: Oxford University Press.

O'Connor, E. (2002). Storied business: tipology, intertextuality, and traffic in entrepreneurial narrative. The Journal of Business Communication, 39(1), 36-54. http://dx.doi.org/10.1177/002194360203900103

Oliveira, S. A., \& Bulgacov, Y. L. M. (2013). Wittgenstein e a administração: potencialidades da pragmática da linguagem aos estudos organizacionais e à estratégia. Revista de Administração Contemporânea, 17(5), 556-573. Recuperado de http://www.scielo.br/pdf/rac/v17n5/v17n5a05.pdf. http://dx.doi.org/10.1590/S1415-65552013000500004

Pentland, B. T. (1999). Building process theory with narrative: from description to explanation. $\begin{array}{llll}\text { Academy of Management } & \text { Review, 24(4), }\end{array}$ http://dx.doi.org/10.5465/AMR.1999.2553249 
Phillips, N., \& Oswick, C. (2012). Organizational discourse: domains, debates, and directions. The Academy of Management Annals, 6(1), 435-481. http://dx.doi.org/10.1080/19416520.2012.681558

Rasche, A., \& Chia, R. (2009). Researching strategy practices: a genealogical social theory perspective. Organization Studies, 30(07), 713-734. http://dx.doi.org/10.1177/0170840609104809

Reckwitz, A. (2002). Toward a theory of social practices a development in culturalist theorizing. European Journal of Social Theory, 5(2), 243-263. http://dx.doi.org/10.1177/13684310222225432

Rouleau, L. (2010). Studying strategizing through narratives of practice. In D. Golsorkhi, L. Rouleau, D. Seidl, \& E. Vaara (Eds.), Cambridge handbook of strategy as practice (pp. 258-270). Cambridge: Cambridge University Press. http://dx.doi.org/10.1017/CBO9780511777882.018

Samra-Fredericks, D. (2003). Strategizing as lived experience and strategists' everyday efforts to shape strategic direction. Journal of Management Studies, 40(1), 141-174. http://dx.doi.org/10.1111/1467-6486.t01-1-00007

Smets, M., Greenwood, R., \& Lounsbury, M. (2015). An institutional perspective on strategy as practice. In D. Golsorkhi, L. Rouleau, D. Seidl, \& E. Vaara (Eds.), The Cambridge handbook of strategy as practice (2nd ed., pp 283-300). Cambridge: Cambridge University Press. http://dx.doi.org/10.1017/CBO9781139681032.017

Søderberg, A. M. (2003). Sensegiving and sensemaking in an integration processes. In B. Czarniawska \& P. Gagliardi (Eds.), Narratives we organize by (Vol. 11, pp. 3-35). Sweden: John Benjamins Publishing.

Suddaby, R., Seidl, D., \& Lê, J. K. (2013). Strategy-as-practice meets neo-institutional theory. Strategic Organization, 11(3), 329-344. http://dx.doi.org/10.1177/1476127013497618

Vizeu, F.; \& Gonçalves, S. A. (2010). Pensamento estratégico: origens, princípios e perspectivas. São Paulo: Atlas.

Walter, S. A., \& Augusto, P. O. M. (2011). A institucionalização da estratégia como prática nos estudos organizacionais. Revista de Administração, 46(4), 392-406. http://dx.doi.org/10.5700/rausp1019

Walter, S. A., Augusto, P. O. M., \& Fonseca, V. S. (2011). O campo organizacional e a adoção de práticas estratégicas: revisitando o modelo de Whittington. Cadernos EBAPE. BR, 9(2). http://dx.doi.org/10.1590/S1679-39512011000200005

Weick, K. E. (1995). Sensemaking in organizations. California: Sage Publications.

Whittington, R. (1996). Strategy as practice. Long Range Planning, 29(5), 731-735. http://dx.doi.org/10.1016/0024-6301(96)00068-4

Whittington, R. (2002). The work of strategizing and organizing: for a practice perspective. Strategic Organization, $1(1)$, 119-127. http://dx.doi.org/10.1177/147612700311006

Whittington, R. (2004). Strategy after modernism: recovering practice. European Management Review, l(1), 62-68. http://dx.doi.org/10.1057/palgrave.emr.1500006

Whittington, R. (2006). Completing the practice turn in strategy research. Organization Studies, 27(5), 613-634. http://dx.doi.org/10.1177/0170840606064101

Wilkinson, D., \& Birmingham, P. (2003). Using research instruments: a guide for researchers. London: Routledge Falmer. 
Wilson, D. C., \& Jarzabkowski, P. (2004). Thinking and acting strategically: new challenges for interrogating strategy. European Management Review, 1(1), 14-20. http://dx.doi.org/10.1057/palgrave.emr.1500008

Wittgenstein, L. (2000). Investigações filosóficas (Os Pensadores). São Paulo: Nova Cultural.

\title{
Dados dos Autores
}

\author{
Natália Rese \\ Av. Prefeito Lothario Meissner, 632, 80210-170, Curitiba, PR, Brasil. E-mail: resenati@ gmail.com \\ Flávia Harumi Souza Kuabara \\ Av. Prefeito Lothario Meissner, 632, 80210-170, Curitiba, PR, Brasil. E-mail: flavia.kuabara@ gmail.com \\ Eduardo Guedes Villar \\ Av. Prefeito Lothario Meissner, 632, 80210-170, Curitiba, PR, Brasil. E-mail: eduardogvillar@ gmail.com \\ Jane Mendes Ferreira \\ Av. Prefeito Lothario Meissner, 632, 80210-170, Curitiba, PR, Brasil. E-mail: janemff@yahoo.com.br
}

